\title{
Desafios do território em transformação: o Complexo Portuário do Açu e seus reflexos socioeconômicos
}

Alcimar das Chagas Ribeiro

Elza Maria Gonçalves Campos Matos*

\begin{abstract}
Resumo
O trabalho investiga a possibilidade de o território de influência direta do Complexo Portuário do Açu, mais especificamente, Campos dos Goytacazes e São João da Barra - RJ, coordenar um processo voltado para a ação coletiva, enquanto fundamento essencial para assegurar desenvolvimento em um contexto de investimento exógeno. Metodologicamente, utilizase o instrumental da Teoria Institucional, pela qual alguns elementos são sistematizados e aplicados na abordagem às principais lideranças dos setores público e privado. A síntese dos resultados indica um perfil sociocultural inibidor da ação coletiva no território, uma prática da autovalorização do papel individual de cada entidade, além da dificuldade de integração dos atores e agentes a movimentos de caráter coletivo.
\end{abstract}

Palavras-chave: desenvolvimento; arranjo institucional; ação coletiva; economia institucional.

\begin{abstract}
The paper investigates the possibility of direct influence of the territory of the Acu port complex, more specifically, Campos dos Goytacazes and São João da Barra - RJ, to coordinate a process focused on collective action as an essential foundation for ensuring development in a context of inward investment. Methodologically, it uses the tools of institutional theory, where some elements are highlighted and applied in addressing the major leaders in the public and private sectors. A summary of the results indicates a sociocultural profile inhibitor of collective action in the territory, a practice the high appreciation of the individual role of each entity, apart from the difficulty of integrating the actors and agents with movements of collective character.
\end{abstract}

Keywords: development; institutional arrangement; collective action; institutional economics.

\footnotetext{
* Alcimar das Chagas Ribeiro: Economista pelo Instituto Metodista Bennett, mestre e doutor em Engenharia de Produção pela Universidade Estadual do Norte Fluminense Darcy Ribeiro - UENF e professor pesquisador da UENF. E-mail: professoralcimar@gmail.com Elza Maria Gonçalves Campos Matos: Administradora de empresas pelo Instituto Federal Fluminense, mestre em Engenharia de Produção pela Universidade Estadual do Norte Fluminense Darcy Ribeiro - UENF. E-mail: adm_elza@hotmail.com
} 


\section{Introdução}

A região Norte Fluminense vem recebendo um importante fluxo de investimento público e privado, dirigido para o setor de petróleo e infraestrutura portuária, fato que tem provocado mudanças no território, transformando sua base econômica de característica agropecuária para uma economia industrial de grande proporção.

Os transtornos ocasionados com essa mudança geram fortes expectativas sobre a população local, além de gerar muitas dúvidas aos estudiosos sobre as reais possibilidades de que estes investimentos sejam convertidos em melhoria de qualidade de vida para a população. Esta é uma preocupação recorrente, já que o processo de desenvolvimento não resulta apenas de taxas positivas originárias do crescimento do PIB, mas, sobretudo, deve implicar a melhoria constatável do padrão de vida da maioria da população (Souza et al., 2009; Junior et al. 2011; Ribeiro et al., 2011; Salles e Ribeiro, 2011).

Partindo desse ponto, admite-se que, para a sociedade local alcançar melhoria no seu padrão de vida, é necessária uma rápida adaptação à nova configuração produtiva. No entanto, essa adaptação deve decorrer de processos delicados de negociação em que a autonomia esteja presente e os mecanismos específicos de coordenação se façam sob o controle democrático da sociedade e com expressão valorizada da população local. Caso contrário, é iminente o risco do não desenvolvimento ou de um desenvolvimento não sustentável e agressivo social e ambientalmente.

A teoria institucional orienta para a promoção do desenvolvimento econômico amparado na estrutura de uma governança territorial, capaz de assegurar a cooperação voluntária entre as partes em um sistema de troca impessoal. Como não há vínculos entre as partes neste sistema, a cooperação depende da confiança proporcionada pelas instituições. Portanto, um arranjo institucional deve ser criado para governar as maneiras pelas quais as unidades econômicas, que nunca são apenas econômicas senão também sociais, nesses sistemas, possam cooperar e/ou competir. Ou seja, na falta de confiança pessoal, torna-se absolutamente fundamental que a "liga" das relações se construa e se consolide por um substituto que, na perspectiva institucionalista, é a confiança institucional que, por sua vez, é estabelecida pelo arranjo institucional (North, 1990; Williamson, 1993; 2000).

Tal confiança é proporcionada pelo arranjo institucional, segundo Williamson (2000), na medida em que esse atue de forma a minimizar custos de transação, o que consequentemente possibilita a cooperação entre duas partes envolvidas na transação. Contudo, Bueno (2011) alerta que, além dos custos de transação, existem os dilemas de ação coletiva que podem inibir o comportamento cooperativo dos indivíduos, e ressalta ainda que os problemas coletivos não podem ser tratados com as mesmas estratégias utilizadas nas transações entre duas partes (Bueno, 2011). Assim a questão que resta ser respondida é: o território possui um arranjo institucional capaz de articular uma estratégia que seja capaz de assegurar um comportamento cooperativo entre os agentes econômicos no território e, por outro lado, forneça guias de ação que permitam aos investimentos exógenos direcionados para a região traduzirem-se em desenvolvimento socioeconômico para a população local?

O objetivo do trabalho é, portanto, verificar se o processo de interação entre as lideranças locais permite a articulação de estratégias necessárias para a inserção da população local nas mudanças provocadas pelos investimentos exógenos, direcionados para o território. O trabalho, baseado em uma pesquisa de mestrado, aponta fragilidades nas iniciativas de caráter coletivo e ressalta a difícil condição de adaptação dos agentes e atores ao processo de transformação socioeconômico do território. 
Em sua organização, o trabalho está dividido em cinco seções, além da presente Introdução. Na primeira seção é apresentado o debate teórico sobre arranjos institucionais, ação coletiva e capital social. Na segunda, é delineada uma breve caracterização da situação local, ressaltando os aspectos relevantes ao entendimento do ambiente em mudanças. A seção três é destinada à apresentação dos aspectos metodológicos. Na quarta seção, são expostos os resultados da pesquisa e discussões. Por fim, são feitas considerações finais do estudo.

\section{1 - Referencial teórico}

A sustentação teórica do presente trabalho se deu através dos fundamentos da Teoria Institucional, tratada por Veblen, North e Williamson, além de, no intuito de fortalecer a argumentação a respeito do comportamento cooperativo voluntário do indivíduo, se embasar em conceitos da ação coletiva e capital social, contudo sem a pretensão de se aprofundar nesse tema.

\subsection{Instituições e arranjo institucional}

O desenvolvimento econômico de uma nação depende de um ambiente institucional que assegure direitos de propriedade eficientes, uma vez que, no sistema de troca impessoal, como o adotado nas economias modernas, a falta de vínculos entre os indivíduos inibe a cooperação voluntária entre as partes no processo produtivo (North, 1990). Essa desconfiança produz os custos de transação, os quais são explicados pelos pressupostos de que os indivíduos possuem capacidade limitada e estão propensos a ter comportamentos oportunistas. Assim, a forma de assegurar benefícios mútuos em uma transação é através da criação de instituições que minimizem os custos de transação, assegurem direitos de propriedade e promovam a confiança institucional (Bueno, 2004). Contudo, além de um ambiente institucional que minimize custos de transação, Williamson (2000) adverte que o desenvolvimento econômico requer também a estruturação de arranjos institucionais com a função de governar as maneiras pelas quais as unidades econômicas podem cooperar e/ou competir. Complementa Conceição (2002) que não se pode esperar que o ambiente institucional regule os processos realizados em meio à absoluta incerteza.

No entanto, nas transações que envolvem um maior número de agentes, a cooperação pode ser inviabilizada, não apenas pelos custos de transação, mas também pelos dilemas de ação coletiva (Bueno, 2011). Para tratar tais dilemas, faz-se necessário o engendramento de estruturas de governança com a função de assegurar a confiança entre grupos, visando incentivar o comprometimento desses com objetivos comuns (Nunes, 2009). E, nesse caso, as instituições se transformam em ente da ação coletiva, passando a serem entendidas como unidades sociais direcionadas ao alcance de objetivos coletivos que influenciam o desenvolvimento e, através "da sua estrutura normativa e reguladora, implicam a mediação de diferentes esferas de poder e interesses divergentes, os quais são construídos e transformados pelos atores ao longo do tempo pela interação social” (Nunes e Schneider, 2012:8).

Segundo Gomes et al. (2008), enquanto nas transações entre duas partes a confiança pode ser estabelecida por arranjos institucionais que assegurem ganhos mútuos, a ação coletiva, que é sustentada pelo princípio da solidariedade e da cooperação, depende das relações sociais. Estas possibilitam o surgimento da confiança, elemento fundamental para permitir o comportamento cooperativo entre grupos. Ou seja, as relações sociais, na medida 
em que possibilitam o surgimento do comportamento cooperativo, são os mecanismos para evitar o problema da ação coletiva, o que impede as comunidades de perceberem os benefícios da cooperação (Bueno, 2011).

Além das relações sociais, a construção da ação coletiva exige uma estratégia articulada e coordenada entre os vários grupos de interesse (Haguette, 2005, apud Junior et al., 2007). O papel da coordenação é coagir e delimitar as controvérsias e assim assegurar que os indivíduos realizem seus intuitos (Nunes e Schinider, 2012). É também função da coordenação minimizar as incertezas quanto aos resultados da ação coletiva, o que exige mecanismos de restrição e de incentivos que possibilitem ao grupo vislumbrar possíveis ganhos (Ostrom, 2007, apud Junior, 2007), além de buscar acomodar o comportamento individual de acordo com os interesses coletivos (Haguette, 2005, apud Junior, 2007). Para Ostrom (1999, apud Teixeira, 2008), as pessoas não irão aderir a objetivos coletivos, caso não haja alguma forma de convencimento, o que evidencia a relevância da presença de líderes, cuja responsabilidade inclui as mobilizações populares, conforme aponta Levi:

\begin{abstract}
As instituições resolvem problemas de ação coletiva trazendo à tona contribuições de indivíduos que, por sua vez, não conseguem realizar seus desígnios a não ser que alguém (ou algumas pessoas) tenha o poder de coordenar, ou coagir termos e delimitar os efeitos das controvérsias. (Levi, 1991, apud Gomes et al., 2008:3)
\end{abstract}

Evidencia-se, assim, que a cooperação voluntária na ação coletiva exige a presença de líderes para coordenar os esforços e o desenvolvimento de uma estratégia, visando minimizar as incertezas quanto aos resultados da ação. No entanto, a decisão do indivíduo em cooperar é influenciada pelos laços coesos existentes entre os indivíduos (North, 1990). São esses os laços que definem o estoque de capital social presente em um determinado território, o qual exerce papel fundamental na decisão do indivíduo em agir cooperativamente (Athayde e Ribeiro, 2011).

O capital social é definido como um conjunto de características específicas da organização social, tais como laços de confiança, normas, sistemas, redes de interação e cadeias de relações sociais, e é gerado na integração social (Putnam 1993, apud Gomes et al. 2008; Muls, 2008). Embora seja um aliado imprescindível ao desenvolvimento, o estoque de capital social em um território pode ser insuficiente para promover o comportamento cooperativo espontâneo do indivíduo e, neste caso, se fazem necessárias ações do Estado que o promovam. O governo deve conscientemente criar mecanismos de ação coletiva com o intuito de atuar em uma determinada situação. Conforme afirma Conceição:

\footnotetext{
ainda que Commons aceite que os costumes, as normas e as regras possam surgir espontaneamente, assinala o decisivo papel da ação coletiva consciente do governo na solução de conflitos entre as instituições, o que sugere que o papel das instituições (e dos mecanismos de ação coletiva) é assegurar certa "ordem” ao funcionamento do sistema. (Conceição, 2008)
}

Observa-se ainda que a ação do Estado é necessária para incentivar e proporcionar a cooperação e a sinergia entre os atores em nível local e assim diminuir o conflito e estimular o desenvolvimento (Putnam, 1993 apud Nunes e Schneider, 2012). Para North (1990), o papel do Estado é promover a interação institucional de forma democrática e transparente, com o objetivo de estimular o desenvolvimento, uma vez que

Tomando por base a colocação de Hodgson (1994), no âmbito local as instituições assumem um caráter que faz referência ao que se define enraizamento (embeddedness). Assim, quando se faz referência ao contexto institucional local, dar-se-á importância ao arranjo institucional relevante para localidades geográficas específicas. (Nunes e Schneider, 2012:8) 
Contudo esse processo que envolve a presença do Estado na promoção do capital social, entendido como um mecanismo que possibilita o desenvolvimento econômico, diz respeito à coordenação da ação coletiva e à orientação para a formação de novos arranjos institucionais. Estes são formados por meio de redes de relações que se configuram pelas parcerias organizacionais que buscam dar conta das necessidades e estratégias traçadas (Büttenbender, 2010). Também se configura em uma governança territorial, uma forma de coordenação política entre os diversos atores de um território, através da discussão e definição de objetivos coletivos (Leloup et al., 2004, apud Silva, 2007).

Conclui-se que o desenvolvimento econômico possui uma interdependência entre os arranjos institucionais, engendrados para potencializar a ação coletiva. Esta depende da presença de capital social, fator determinante da capacidade de as pessoas cooperarem voluntariamente, uma vez que possibilita o surgimento da confiança, elemento fundamental para superar o dilema da ação coletiva. Assim, os arranjos institucionais, além de minimizar custos de transação, promovem o capital social de um território e facilitam o surgimento do comportamento cooperativo entre os indivíduos, os quais visam atingir objetivos coletivos.

\section{2 - Caracterização da situação local}

O território em análise compreende os municípios de São João da Barra e Campos dos Goytacazes, na Região Norte Fluminense, RJ. Esses municípios são os mais impactados pelos investimentos privados do Complexo Industrial Portuário do Açu - CIPA, apresentado na Figura 1.

Figura 1

Complexo Industrial Portuário do Açu - CIPA

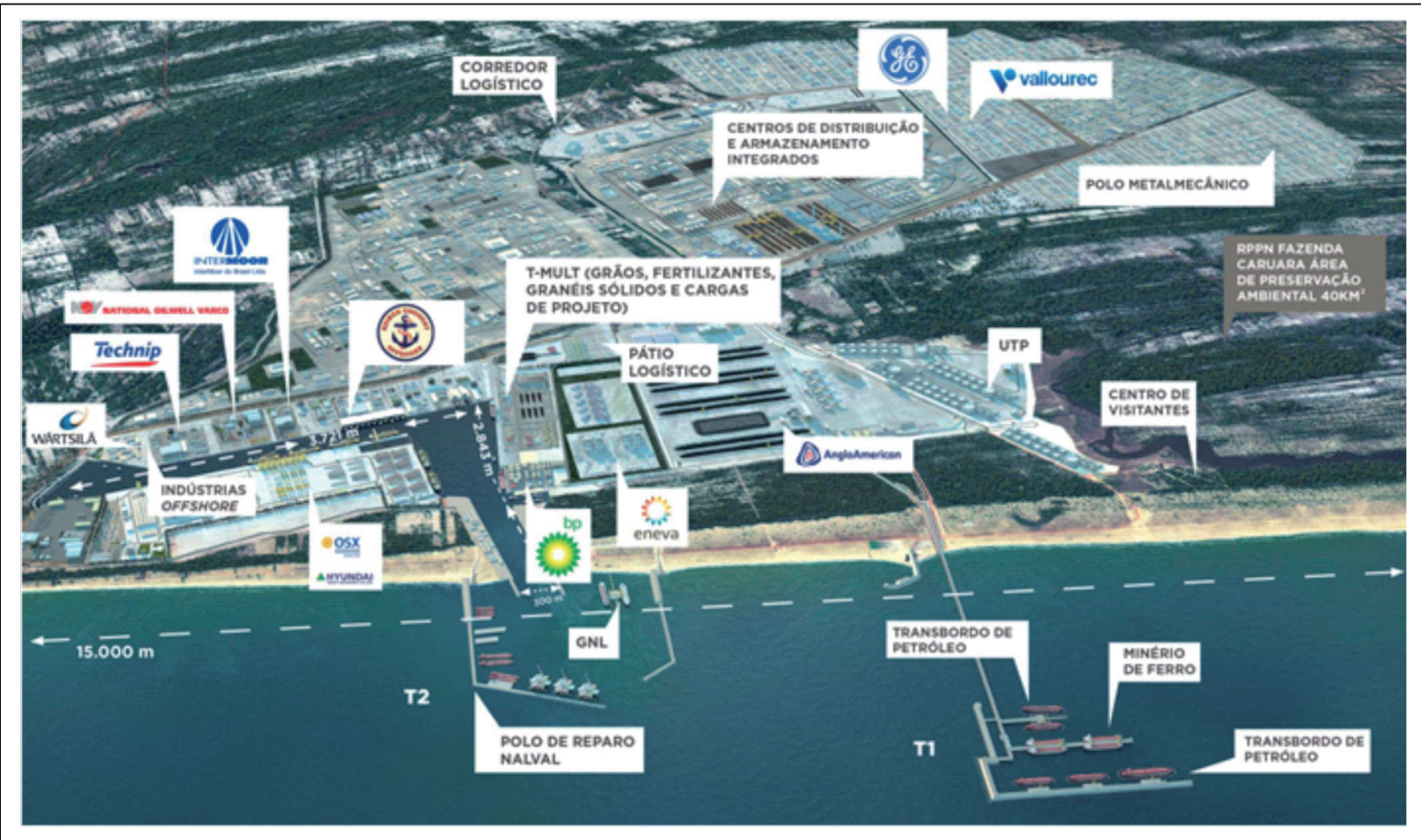

Fonte: http://www.prumologistica.com.br/superporto-do-acu 
Trata-se de um grande empreendimento que traz em seu bojo grandes expectativas em relação à oferta de emprego, melhoria da qualidade de vida, mudança na estrutura produtiva de base rural, mas também traz impactos negativos relacionados à interferência no meio ambiente e os relacionados ao aquecimento da tensão social, em função dos conflitos gerados pelas desapropriações de terras.

Importante observar que o modelo inicial pensado para o Complexo Portuário do Açu sofreu forte esgotamento, em função da perda de credibilidade do seu principal empreendedor. Assim, o redirecionamento marca a segunda fase do projeto, em que o foco na concepção "porto indústria", que materializou a ideia do "Distrito Industrial”, dá lugar às atividades de escoamento de minério e de fornecimento de bens e serviços para a atividade petrolífera. A Figura 1 representa a configuração atual do complexo, onde a Prumo Logística substituiu a LLX do empresário Eike Batista na coordenação do processo de construção do Porto do Açu.

\section{3 - Metodologia}

Esta seção é dedicada à descrição dos procedimentos metodológicos que foram empregados para analisar o território que sofre influência direta do CIPA.

\subsection{Natureza da pesquisa}

Este trabalho possui cunho exploratório, uma vez que provoca a emergência de vários aspectos relativos ao fato em estudo, seja por meio de levantamento bibliográfico, que mapeia abordagens convergentes sobre o tema, seja por meio de entrevistas com os atores responsáveis pelas organizações que compõem o arranjo institucional do território. Assim, o delineamento e as técnicas utilizadas, apresentadas a seguir, visam assegurar que a pesquisa atinja seu objetivo (Gil, 2002).

O método de pesquisa utilizado foi o estudo de caso, indicado para pesquisa qualitativa, particularmente quando se trata de um fenômeno contemporâneo sobre o qual o pesquisador não possui controle, o que se adequa ao problema proposto. Esse método, segundo Becker (1999), tem se tornando "uma das principais modalidades de análise das Ciências Sociais”, sendo viável para o estudo de um único indivíduo, uma organização ou uma comunidade (Becker, 1999). Para a descrição do caso e compreensão do problema, foram coletados dados da população por meio de entrevistas junto às principais lideranças que atuam nas organizações sociais território.

\subsection{Participantes}

Participaram da pesquisa doze entrevistados de onze organizações diferentes, subdivididas em organizações de ensino, apoio financeiro e tecnológico, entidades de classe, setor público e setor privado. São elas: 1) Ensino: Universidade Estadual Norte Fluminense Darcy Ribeiro UENF, representada por dois informantes, o reitor e um pesquisador ; 2) Apoio Financeiro e Tecnológico: Fundo de Desenvolvimento de Campos dos Goytacazes - FUNDECAN, representada pelo presidente da instituição; Fundação Estadual Norte Fluminense - FENORTE, representada por seu presidente; Serviço Brasileiro de Apoio a Micro e Pequena Empresa - SEBRAE, representada pelo gerente regional de Campos de Goytacazes; e Serviço Nacional de Aprendizagem Industrial - SENAI, representada pelo 
gerente da unidade de Campos; 3) Entidade de Classe: Associação Comercial e Industrial de Campos - ACIC, representada pelo presidente; Associação dos Produtores Rurais e Imóveis ASPRIM, representada por uma associada; Sindicato Rural de Campos dos Goytacazes - SRCG, representada pelo seu presidente e Sindicato Rural de São João da Barra - SRSJB, também representada por seu presidente; 4) Setor público: Secretaria Municipal de agricultura de São João da Barra - SMASJB, representada pelo secretário municipal.

\subsection{Coleta de dados}

A técnica de coleta de dados utilizada foi a entrevista, a qual possibilita, por meio de relatos verbais dos participantes, a obtenção de informações de amplo espectro, direta ou indiretamente ligadas ao tema em estudo, ampliando sobre determinados aspectos o caráter exploratório da pesquisa. Outra vantagem da entrevista é oferecer um contato direto entre entrevistador e entrevistado, o que possibilita uma melhor comunicação, uma vez que, no contato face a face, desde que precedido pelo devido rapport, o pesquisador pode corrigir enganos do entrevistado e vice-versa. Assim, embora a entrevista tome maior tempo do entrevistador, essa técnica, na maioria dos casos, representa uma melhor amostra da população, uma vez que as pessoas normalmente gostam de falar com aqueles que se mostram interessados por seus problemas (Selltiz et al., 1987; Yin, 2005).

Nas entrevistas foram utilizadas perguntas abertas, usadas para questões que solicitam razões e explicações, e optou-se por mais de uma questão, uma estratégia utilizada na tentativa de obter respostas ao problema de pesquisa (Cervo, 1983:23).

\subsection{Pesquisa de campo e seleção da amostra}

A pesquisa de campo foi desenvolvida em quatro etapas. A primeira consistiu no desenvolvimento de um roteiro de perguntas abertas para ser utilizado nas entrevistas com o objetivo de identificar como ocorre o processo de articulação intra-arranjo institucional e entre este e a sociedade, além de checar se o arranjo buscava fortalecer as relações sociais.

O roteiro é iniciado com uma introdução, na qual se esclarecem a motivação e o objetivo da pesquisa e se apresentam ao entrevistado as premissas do estudo. Ou seja, é um momento de esclarecimento recíproco, no qual o pesquisador comenta acerca dos vultosos investimentos exógenos direcionados à infraestrutura portuária da Região Norte Fluminense e seus impactos sobre a configuração produtiva local, e que exigem uma rápida adaptação da população local como condição para que estes investimentos se traduzam em desenvolvimento, o que não ocorrerá automaticamente. Esclarece também que, diante dessa premissa, o intuito da pesquisa é obter informações que possibilitem verificar se o território possui um arranjo institucional articulado de acordo com os fundamentos da Teoria Institucional, pressuposto para potencializar a ação coletiva visando a um objetivo comum. Assim o roteiro foi elaborado com o objetivo de integrar da forma mais esclarecida possível e não delimitar o entrevistado. Além da introdução, foram formuladas três perguntas buscando atender aos objetivos específicos da pesquisa.

A segunda etapa da pesquisa consistiu na seleção da amostra da população a ser pesquisada por meio de um levantamento de dados secundários junto à Pro-reitoria de Extensão da UENF. Esta permitiu a seleção de vinte e duas instituições de interesse no problema em questão, conforme já citadas anteriormente. Apesar do esforço no contato com as organizações, participaram efetivamente da pesquisa onze entrevistados de dez instituições, conforme estabelecido no item 3.2. 
O terceiro passo do trabalho consistiu no contato com as instituições para o agendamento das entrevistas com os representantes de cada instituição. Nesta etapa, o contato foi feito pessoalmente pelo pesquisador, o qual coletou todas as informações necessárias, ao mesmo tempo em que construía a rede de relacionamento para a pesquisa, cuidado particularmente importante na abordagem qualitativa, para a qual a coleta de dados não é meramente um momento burocrático da pesquisa, mas constitui o seu ponto central. Em seguida, o pesquisador enviou a solicitação da entrevista por meio de e-mails. Assim, no período de 06 de fevereiro a 10 de junho de 2013, iniciou-se a quarta etapa da pesquisa que consistiu na realização das entrevistas com os representantes das onze instituições participantes.

\subsection{Realização das entrevistas}

As entrevistas foram gravadas, com uma duração de 50 a 70 minutos. Após o término, essas foram transcritas na íntegra para que fosse possível, em um segundo momento, proceder à manipulação das mensagens que corresponderiam às perguntas do roteiro, pois, por se tratar de perguntas abertas, as respostas não são diretas, sendo essa uma característica desse procedimento de pesquisa que exige, para a análise dos dados, um processo extenso e exaustivo.

\subsection{Análise de dados}

Para a análise dos dados foi feita a opção pela análise de conteúdo, definida como "um conjunto de técnicas de análise das comunicações, que utiliza procedimentos sistemáticos e objetivos de descrição de conteúdo das mensagens" (Bardin, 1977:38). Esta opção foi feita por ser um método que oferece a oportunidade de inferência ao pesquisador a partir do tratamento e manipulação das mensagens.

\subsection{Limitações metodológicas}

A utilização de pesquisas exploratórias através do estudo de caso traz limitações para a generalização dos resultados obtidos, em função das características próprias que cada unidade de pesquisa possui. São de difícil replicação em função da impossibilidade de padronizar os instrumentos de coleta de dados e possui um processo de análise complexo por se tratar, como neste caso, de uma pesquisa qualitativa (Gil, 1999).

No entanto, apesar das limitações existentes, acredita-se que o caráter exploratório se justifica, pois é capaz de trazer informações relevantes do contexto no qual ocorre o fenômeno estudado.

\section{4 - Resultados e discussão}

Sinalizações vindas da vasta literatura internacional, sobre o tema desenvolvimento econômico, têm indicado que o mesmo processo depende de um arranjo institucional ou de uma estrutura de governança para gerenciar as formas como as unidades econômicas podem cooperar/competir. Esta afirmativa possibilitou a primeira pergunta da presente pesquisa: "Na opinião do (a) senhor (a), os investimentos dirigidos para o porto do Açu garantem automaticamente desenvolvimento econômico no território?"

Segundo o representante da ASPRIM, a riqueza que está sendo gerada no território vai melhorar a vida de poucos e não gerará prosperidade para a população. Em sua opinião, 
nesses seis anos de obras do porto, a prosperidade está andando para trás, e conclui: "É como se o desenvolvimento estivesse andando para trás para os agricultores”. Já para o representante do Sindicato Rural de São João da Barra, o desenvolvimento ocorreria apenas para o Grupo EBX, que teria expulsado a população de suas terras. Complementou ainda que, provavelmente, a população ficará apenas com o ônus desse empreendimento (importante lembrar que na primeira configuração o grupo X liderava o empreendimento).

O representante da FENORTE afirmou que ainda não se tem desenvolvimento na região, pois os investimentos, no primeiro momento, só foram capazes de promover piora na qualidade de vida das pessoas, aumento do tráfego e demanda por moradia.

Para o representante do SEBRAE, não há como promover o desenvolvimento sem gerar problemas e, assim, o que ocorre no território é uma consequência natural do desenvolvimento, e sugere: "Se faz necessário o desenvolvimento de ações que visem mitigar esses problemas".

Na segunda pergunta buscou-se entender a percepção dos atores sobre a existência no território de um arranjo institucional articulado, para melhor adaptação da população ao contexto de mudanças.

Na compilação dos resultados, foi verificada uma convergência entre os informantes para a existência de uma estrutura de governança. Representantes da UENF, FENORTE e FUNDECAM justificam suas afirmações através de ações desenvolvidas antes mesmos das obras do Porto do Açu. O representante da FUNDECAM afirma que a interação entre as organizações é constante e cita, como exemplo, a capacitação de empreendedores realizada em parceria com o SEBRAE, cujo objetivo é possibilitar que ao receber crédito o empreendedor possa também ter acesso a treinamento gerencial.

O representante do SEBRAE entende que a entidade possui uma boa articulação com a empresa LLX, exemplificando a implementação do projeto que visa inserir a MPE nesse processo de mudanças. O objetivo do projeto é capacitar os empresários das MPE para atender à demanda do porto, uma vez que este possui exigências às quais os empreendedores do território não estão preparados para atender. No entanto, acrescenta que, excetuando-se a parceria com a LLX, há apenas algumas ações em parceria com a FIRJAN.

O representante da SMASJB indica que a entidade desenvolve ações em conjunto com a Empresa LLX. Ressalta que é primordial pensar na inserção do produtor agrícola nesse processo, já que é o que ele sabe fazer. Explica ainda o esforço dentro do plano diretor para a conservação das áreas tradicionais de produção do município e acrescenta que é necessário desenvolver ações para manter o trabalhador rural no campo.

Os representantes do SRCG, SRSJB e da ACIC apresentam posições convergentes em relação à existência no território de um arranjo institucional. Porém, enquanto para primeiro tal arranjo não ouve a população local e assim age de acordo com o que entende ser bom para o município, o segundo diz que: "Falta é vontade política de querer fazer para a população local, pois até o presente momento o que foi feito foi para beneficiar o grupo que está vindo de fora”. Para o representante da ACIC, as organizações do território agem individualmente e, para o enfrentamento às mudanças, sugere que as organizações atuem em união de modo a somar forças.

Já o pesquisador de políticas sociais argumenta que, se houvesse uma articulação entre as instituições, pensando a adaptação local, os grupos de pesquisas já consolidados no território - tais como aqueles que promovem discussões sobre as características da região; aqueles que têm tentado pensar em torno de um projeto alternativo para região; e aqueles que 
discutem a questão dos royalties - não teriam sidos ignorados. E, então, conclui afirmando que "essa chamada sociedade organizada não tem uma visão de desenvolvimento, mas estão aferradas a uma visão de crescimento".

A argumentação do representante da ASPRIM é de que, na região, a população tem que escolher entre estar do lado do governo e dizer sim a tudo que lhe interessa, ou buscar a independência e ser massacrada pelo poder público e empresa privada. Dessa forma, as associações foram cooptadas pelo governo municipal por não apresentarem autonomia. Essa foi a razão para a criação de uma nova associação, pois as que existiam não tinham como combater as ameaças dos governos estadual e municipal. E acrescenta que "este governo em momento algum exigiu que se inserisse o agricultor no processo de desenvolvimento". Logo, não existe uma articulação no sentido de promover a adaptação do agricultor que é um dos maiores prejudicados nesse processo.

O representante do SENAI diz que "pelo menos entre as instituições de ensino não há”. Mas que sua instituição desenvolve cursos em parceria com a empresa LLX, cujo objetivo é capacitar profissionais para atuarem nas novas demandas que estão surgindo em virtude da implantação do porto e acrescenta: "Esta é uma forma de inserir a população local neste processo".

A terceira pergunta busca entender o processo de interação entre os atores ao planejar e coordenar ações visando solucionar conflitos e assegurar o engajamento das pessoas nessas ações.

Todas as opiniões convergiram para a não existência de tal processo. Contudo, as opiniões podem ser divididas entre aquelas que acusam o poder público e o grupo responsável pela implantação do empreendimento de atuarem de forma a agravar os conflitos no território e aquelas que entendem que a posição destes está correta.

Na opinião do pesquisador da UENF, o Estado e o grupo EBX coordenaram a invasão das terras dos produtores agrícolas. Os conflitos gerados devido a essas desapropriações foram tratados de forma autoritária e violenta, através de ações unilaterais do Estado em conjunção com o grupo EBX, aprofundando conflitos e desrespeitando os direitos civis dos cidadãos.

Para o representante do SRSJB, não há um trabalho pensando a interação entre a população e as empresas responsáveis pelo empreendimento. Lamenta que as decisões que envolvem a população e o porto sejam tomadas de cima, ao invés de ser promovida uma discussão com a população local e ressalta: "Não sou contra o progresso, sou contra o desrespeito com que tem sido tratado o homem do campo, o qual não tem voz”.

A mesma liderança esclarece que a forma de relacionamento que existe hoje entre a população e o grupo responsável pela implantação do porto é a audiência pública, mas argumenta que "esta só vêm comunicar, ela não vem ouvir o cidadão sanjoanense [...] tudo o que se argumenta nessas audiências tem uma resposta que não nos convence, mas é a que prevalece".

Para o representante do SEBRAE, a articulação de uma estratégia junto às entidades de classe é um desafio, pois essas possuem dificuldade em participar de ações conjuntas, seja por falta de conhecimento da missão da entidade, seja por falta de interesse pelo coletivo. Dessa forma, a solução encontrada pela organização, em um primeiro momento, foi "formatar" junto com a empresa LLX um modelo de inserção da MPE no processo e, em um segundo momento, apresentar o projeto para a sociedade. 
O representante do SRSJB afirma que interage com as demais organizações, pois participa de todas as reuniões e eventos para os quais é convidado e opina: "Seria muito importante uma coordenação que pensasse no agricultor, porque esse tem sido marginalizado". E argumenta que a UENF tem demonstrado, devido aos trabalhos desenvolvidos em prol da agropecuária, ser uma organização que poderia estar à frente dessa coordenação.

Já o representante do SRCG entende que não existem ações coordenadas específicas para o local; o que pode haver, em sua opinião, são algumas ações para a região. Conclui não acreditar que exista uma coordenação de ações que considere as especificidades do local.

Para o representante do SENAI, além de não haver uma interação entre as organizações, em sua opinião, não há possibilidade de articulação entre as organizações visando um objetivo comum. Complementa que as instituições de ensino, embora possuam o mesmo objetivo, atuam de maneira individual.

O informante representante da SMASJB, que ora se identifica como secretário da agricultura, ora como pesquisador da UFRRJ, justifica que, embora as parcerias ainda sejam tímidas, elas ocorrem com outras instituições públicas. E cita ações da UFRRJ como: o processo de difusão de tecnologia junto aos produtores há algum tempo; recente parceria com a LLX; e estreito relacionamento com a FUNDENOR e com a PESAGRO.

Enquanto secretário, relata que possui parceria também com as associações de classe para as quais a LLX fornece as máquinas e a secretaria fornece o óleo e manutenção. E finaliza dizendo que tem um contato bom com todas as associações, exceto com uma que tem se colocado em posição contrária às decisões do município, mas todas que querem, e ou solicitam os seus serviços, têm sido atendidas e que, dessa forma, não entende por que os agricultores reclamam.

Segundo o representante do FUNDECAN, o Conselho Municipal para o Desenvolvimento Sustentável - COMUDES, criado no Município de Campos dos Goytacazes através da lei no 8.217, de 24 de março de 2011, é um esforço para fortalecer as relações sociais entre as organizações do território.

O informante da FENORTE reconhece que o COMUDES é uma forma de fortalecimento das relações sociais; no entanto, em sua opinião, as ações estão muito direcionadas pela prefeitura, sendo necessário que haja algumas mudanças. E acrescenta ainda que sua organização atuará de forma mais efetiva nesse sentido com o parque tecnológico em planejamento, pois envolverá vários atores do território. O informante representante da UENF explica que o mecanismo de articulação entre a universidade e a sociedade é a Agência de Inovação e sugere que a pesquisa fosse estendida ao diretor deste mecanismo, entretanto este dirigente não tinha disponibilidade de agenda para atender à pesquisa.

Outras mensagens que surgiram no decorrer das entrevistas, embora não respondessem às questões apresentadas no roteiro, auxiliam na compreensão do problema de pesquisa.

Segundo o representante do SENAI, a população local não tem o hábito de se envolver. Logo, ainda não teria tomado consciência da dimensão das mudanças que já estão ocorrendo no território e que ainda vão ocorrer. Finaliza afirmando que essa característica cultural dificulta a participação da sociedade nesse processo.

Para o representante das MPE, o desenvolvimento econômico do território depende de uma mudança cultural local, de modo que as pessoas possam então interagir para discutir uma ação, pois no atual momento, em sua opinião, as pessoas não se dispõem a participar para discutir. 
Segundo o representante da ACIC, para enfrentar os obstáculos que estão ocorrendo na região se faz necessário somar forças entre as organizações e acrescenta: "Nós, da ACIC, estamos realizando várias reuniões com os empresários com o propósito de organizar um fórum de desenvolvimento dentro de dois meses, o qual contará com as associações comerciais e prefeitos, tanto da região norte como da região noroeste fluminense".

Na opinião do PPS, devido ao descaso do Estado em relação aos produtores rurais, surgiu a organização social voluntária, o que pode ser benéfico para o aumento do estoque de capital social no território, conforme relata o pesquisador de Ciências Sociais da UENF:

\footnotetext{
A ASPRIM se revelou uma surpresa por se tratar de uma força de resistência que luta contra a ação destrutiva do Porto do Açu. Confesso que fiquei surpreso dessa instituição ter conseguido apontar qualquer nível de resistência a partir de um agrupamento de agricultores que tinham baixíssimo nível de experiência nesse tipo de embate. Trata-se de um combate muito desigual, entre um grupo de agricultores, que jamais tinha tido qualquer experiência de organização política de enfrentamento contra o governo do Estado, governo federal, governo municipal e um grande conglomerado internacional. E a ASPRIM, que não obteve ajuda nem dos sindicatos da região, foi capaz de gerar uma dinâmica que acabou polarizando pessoas da UENF, UFF, IFF. Tenho que reconhecer que uma liderança endógena se tornou militante e de um modo peculiar dessas pessoas, se tornaram pessoas muito ativas politicamente.
}

A representante da ASPRIM faz severas críticas ao governo local, pois em sua opinião o apoio do governo às atividades produtivas do território nesse momento se reflete através de favores aos atores dependentes da parceria com o Grupo EBX, o qual, segundo ela, se aproveita da vulnerabilidade em que a população se encontra, devido à falta de informação e orientação, e faz um trabalho psicológico assustador para amedrontar e causar insegurança e, assim, retirá-la de suas terras sem resistência.

Tal dependência é criticada pelo pesquisador da UENF, o qual entende que "esse grupo não tem interesse em promover ações que beneficiem a localidade, pois a melhoria do modo de vida do povo de São João da Barra não é um problema desse aglomerado”. Este deveria ser um problema local, da prefeitura ou mesmo dos governos estadual e ou federal ao imporem salva-guardas que inibissem o empreendedor de agir de forma oportunista, pois "a prioridade do Grupo EBX não são parcerias que beneficiem a população, a prioridade desse grupo é o lucro”. Logo, não é conveniente que se transfira para este uma responsabilidade que não é sua, pois nenhuma corporação vai investir em algo que não lhe traga ganho econômico efetivo. Questiona como poderia o município de São João da Barra atribuir ao Grupo EBX a proposta do plano diretor, pois deveria ser óbvio que o empreendedor iria ordenar o território a seu bel prazer e argumenta que isso é mais uma demonstração da fragilidade do controle institucional.

Essa opinião também é defendida pelo representante das MPE, ao argumentar que "a LLX tem demonstrado interesse em atuar em parcerias nos projetos com cunho de capacitação das MPE, mas essa não é uma prioridade dos representantes da empresa [...] a prioridade desses é cuidar de seus negócios, o que é perfeitamente compreensível”.

Opinião divergente possui o representante da SMASJB, o qual relata que a LLX propôsse a fazer um plano de compensação em que todas as metas propostas através da UFRRJ fossem atingidas, embora observe que as pessoas que foram para a Vila da Terra ${ }^{1}$ não estão satisfeitas. "Outra preocupação que tivemos foi que o Plano Diretor destinasse 51\% de todo o seu território para ações de agropecuária”.

1 Para minimizar um emergente sentimento de injustiça contra centenas de agricultores familiares, o Grupo EBX estabeleceu uma aldeia rural para receber as famílias expulsas de suas fazendas. Vila da Terra foi apresentada pelo Grupo EBX como um modelo para o reassentamento justo (Pedlowisk e Alvarenga, /2013). 
O pesquisador social relata ainda sua preocupação de que, em um futuro próximo, o descaso do Estado seja com os desapropriados ou com os transtornos que o crescimento gerado pelo empreendimento irá provocar no território. O mesmo processo de crescimento desordenado ocorreu no Município de Macaé, com a chegada da Petrobrás naquele município, o qual apresenta níveis altíssimos de violência, problemas com drogas, invasão de áreas ecologicamente sensíveis. O pesquisador argumenta que esse é resultado de um modelo de crescimento para fora.

Para o informante representante das MPE, o modelo desenvolvido em Macaé tem apresentado ótimos resultados para as MPE da região, e argumenta que as pessoas aqui têm medo da perda de poder, o que justifica a resistência ao CIPA, pois este representa um processo de mudança, principalmente de poder, como ocorre em Macaé, onde o poder está concentrado na Petrobrás, pois tudo gira em seu redor.

Ao ser questionado sobre a crítica à posição alheia da UENF em relação a esse processo, o informante pesquisador rebate:

A UENF não está alheia a esse processo, o problema é que, quando as pessoas procuram as universidades públicas falando em parceria, na verdade elas estão buscando cumplicidade... logo, a melhor forma da universidade contribuir com o desenvolvimento é oferecer uma reflexão de forma autônoma e crítica sobre as limitações desse modelo que foi implantado no território.

Convergente com a opinião de cumplicidade está a representante da ASPRIM, a qual alega que as parcerias entre a empresa LLX e as universidades impediram que essas fossem contra as decisões da empresa.

Em relação ao desenvolvimento econômico, o pesquisador da UENF diz que o Brasil precisa resolver dois problemas: (1) o acesso ao crédito, e cita como exemplo: "A ASPRIM, uma associação de produtores agrícola, não recebeu e nem recebe nenhum tipo de apoio do governo, quer municipal, estadual ou federal, e também não obteve nenhum tipo de aporte financeiro do BNDES. Contrariamente, o empresário Eike Batista, que é um especulador como é de conhecimento de todos, pegou carona com uns grupos para pegar apoio do BNDES"; e (2) a organização de uma ação política, pois "não há como modificar a relação no Estado se você não tiver uma ação política organizada”.

Com objetivo de sintetizar a presente discussão, o Quadro 1 reúne as abordagens realizadas junto aos representantes dos diferentes grupos de interesse, de maneira a facilitar um melhor entendimento do processo. 
Quadro 1

Unidades de análise

\begin{tabular}{|c|c|c|c|}
\hline Organizações & $\begin{array}{c}\text { Desenvolvimento econômico depende } \\
\text { de um processo de governança } \\
\text { institucional! }\end{array}$ & $\begin{array}{l}\text { Existe um processo de governança } \\
\text { institucional em operação, voltado para } \\
\text { o desenvolvimento do território? }\end{array}$ & $\begin{array}{c}\text { Existem estratégias para fortalecer a } \\
\text { interação entre os agentes e facilitar a } \\
\text { ação coletiva? }\end{array}$ \\
\hline ACIC & $\begin{array}{c}\text { Sim. É importante ações no âmbito } \\
\text { coletivo. }\end{array}$ & $\begin{array}{c}\text { Não há ações visando a adaptação da } \\
\text { população. }\end{array}$ & Ações de atração do corpo associado. \\
\hline ASPRIM & $\begin{array}{l}\text { Entende que desenvolvimento teria que } \\
\text { gerar prosperidade e não riqueza para } \\
\text { poucos. }\end{array}$ & $\begin{array}{l}\text { Não há ações visando a adaptação dos } \\
\text { produtores rurais. }\end{array}$ & Inexiste. \\
\hline FENORTE & $\begin{array}{l}\text { Sem um processo de interação } \\
\text { entre as instituições, não há } \\
\text { desenvolvimento. }\end{array}$ & & $\begin{array}{c}\text { Investe em pequenas e grandes } \\
\text { empresas de base tecnológicas, com } \\
\text { o DNA local. }\end{array}$ \\
\hline FUNDECAM & $\begin{array}{l}0 \text { desenvolvimento depende da } \\
\text { atuação de todos os atores. }\end{array}$ & $\begin{array}{l}\text { Há um processo de constante } \\
\text { interação com várias organizações. }\end{array}$ & $\begin{array}{l}0 \text { COMUDES é uma maneira de } \\
\text { fortalecer esse processo de interação. }\end{array}$ \\
\hline SEBRAE & $\begin{array}{l}\text { Desenvolvimento traz problemas. É } \\
\text { importante ações mitigadoras. }\end{array}$ & $\begin{array}{l}\text { Trabalha em parceria com a LLX, } \\
\text { visando capacitar a MPE. }\end{array}$ & $\begin{array}{l}\text { Atua isolado no desenvolvimento da } \\
\text { "espinha dorsal" do projeto ... para } \\
\text { depois "apresentar à sociedade". }\end{array}$ \\
\hline SENAI & & Inexiste. & $\begin{array}{l}\text { Trabalha em parceria com a LLX } \\
\text { visando capacitar profissionais. }\end{array}$ \\
\hline SMASJB & $\begin{array}{c}\text { Há uma preocupação com a } \\
\text { descaracterização do título de } \\
\text { município essencialmente agrícola. }\end{array}$ & $\begin{array}{l}\text { A UFRRJ desenvolve um processo } \\
\text { de difusão de tecnologia junto aos } \\
\text { produtores em parceria com a LLX. }\end{array}$ & $\begin{array}{c}\text { Interação com a FUNDENOR e a } \\
\text { PESAGRO no sentido de desenvolver a } \\
\text { agricultura. }\end{array}$ \\
\hline SRCG & $\begin{array}{l}0 \text { desenvolvimento depende de } \\
\text { organizações que fortaleçam as } \\
\text { atividades local. }\end{array}$ & $\begin{array}{c}\text { Existe, porém a população local não } \\
\text { é ouvida. }\end{array}$ & $\begin{array}{l}\text { Se envolve em projetos visando a } \\
\text { melhoria da nossa classe. }\end{array}$ \\
\hline SRSJB & $\begin{array}{l}0 \text { desenvolvimento somente } \\
\text { beneficiará } 0 \text { grupo } X \text {. }\end{array}$ & $\begin{array}{l}\text { Falta vontade política da parte do } \\
\text { governo. }\end{array}$ & $\begin{array}{c}0 \text { que existe são audiências públicas } \\
\text { que não resolvem, pois elas só vêm } \\
\text { comunicar. }\end{array}$ \\
\hline UENF (pesquisador) & $\begin{array}{l}\text { Essa região tem instituições fracas } \\
\text { para oferecer um contraponto. }\end{array}$ & $\begin{array}{l}0 \text { Estado brasileiro emprega a tática } \\
\text { americana do Vietnam: contenção } \\
\text { localizada do conflito. }\end{array}$ & $\begin{array}{l}\text { A modificação no controle das } \\
\text { oligarquias do Estado depende da ação } \\
\text { coletiva. }\end{array}$ \\
\hline UENF & $\begin{array}{l}0 \text { arranjo institucional é de extrema } \\
\text { importância para o desenvolvimento } \\
\text { econômico da região. }\end{array}$ & $\begin{array}{l}\text { Sim. Informação sobre ações em } \\
\text { planejamento. }\end{array}$ & Não respondeu. \\
\hline
\end{tabular}

Fonte: Elaboração própria (2013).

\section{5 - Considerações sobre os resultados}

$\mathrm{Na}$ presente pesquisa pode-se verificar que a maior parte dos atores desconhece a visão central do arranjo institucional de assegurar a confiança entre as partes no processo produtivo e o fato de que os problemas da não cooperação no território envolvem dilemas da ação coletiva.

Isso fica evidenciado na ausência de mecanismos visando: à promoção da confiança dos produtores rurais no processo de desapropriação de terras; à inibição do comportamento oportunista dos agentes que se instalaram no território; à comunicação com a população local a respeito das mudanças que seriam implantadas no território. A falta de tais mecanismos, além de inibir o desenvolvimento, provocou um ambiente de insegurança e conflitos.

Ao tratar a ação coletiva, foi verificada a ausência dos princípios que norteiam a mesma, pois não se observaram estratégias e nem a presença de liderança visando atingir objetivos coletivos; ou ainda, interação entre os atores. A negação de tais princípios resultou na não adesão da população nas ações propostas pelos atores, além da insatisfação tanto da população local com as decisões tomadas pelos atores locais, pois acusam a governança por tomar decisões de acordo com os critérios estabelecidos por eles e sem ouvir a opinião local, como também dos atores que acusam a população de não gostar de participar de ações conjuntas. E esquecem que cooperar em ação coletiva não é um comportamento natural, mas 
requer um processo de interação capaz de possibilitar a confiança, a solidariedade, ou seja, tal comportamento depende do capital social local.

Considerando ainda que a intervenção do Estado no processo de desenvolvimento é defendida no sentido de proporcionar a geração de capital social a partir de uma interação institucional, verifica-se que esse foi ineficiente, pois utilizou-se da força policial e medidas judiciais para assegurar a efetivação do processo de desapropriação de terras, o que contribuiu para aumentar os conflitos.

Observa-se um equívoco que se cometeu no território ao atribuir a gestão do território à empresa privada, a qual apresenta um projeto de gestão integrada de território - um modelo participativo envolvendo poder público, empresas, organizações da sociedade civil, instituições de educação e lideranças regionais na construção de soluções sustentáveis para o desenvolvimento do município. Contudo, tal modelo não se efetivou, o que já era de se esperar visto que a ação coletiva é de interesse público, sua coordenação não pode ser atribuída a uma empresa privada, a qual possui interesse individual. O que se efetivou foram as ações que interessavam à empresa, ou seja, parcerias entre SEBRAE, SENAI e o agente público local.

Portanto, um equívoco, pois as parcerias entre essas organizações e a empresa privada, buscando uma maior inserção do território ao projeto, parecem não ter atingido o objetivo esperado.

\section{Conclusão}

Conclui-se que o território não possui um arranjo institucional capaz de articular uma estratégia que seja capaz de assegurar um comportamento cooperativo entre os agentes econômicos no território, dado que não fornecem guias de ação que permitam aos investimentos exógenos direcionados para a região traduzirem-se em desenvolvimento socioeconômico para a população local.

Tal resposta é evidenciada visto que mecanismos utilizados, como as audiências públicas, não surtem o efeito desejado pelas lideranças, pois não asseguram o engajamento dos grupos na ação coletiva; o Estado, enquanto agente do contexto local, não norteia suas ações pelos princípios que sustentam a ação coletiva, provocando um ambiente de incertezas e conflitos; as instituições não governamentais constituídas, excetuando a ASPRIM, apresentam forte dependência e submissão ao poder público. Ou seja, essas lideranças não possuem o hábito de intervir no processo decisório, apresentando uma posição passiva diante do poder público.

Conclui-se que o desafio para que o desenvolvimento se efetive no território ainda está na superação do paradigma da mão invisível de Adam Smith, pois a adaptação da população local a esse processo não se dará de forma automática, logo requer uma coordenação de ações. A superação de tal crença deverá permitir que os atores inovem na busca por um modelo de governança territorial alternativo, no qual haja a participação dos vários grupos de interesse na discussão e definição de objetivos coletivos. Um modelo que depende da capacidade de inovação, pois ainda necessita ser criado para localidade. Um modelo que, segundo Ostrom (2007), trata de uma instituição que não pode ser imposta, mas que deve ser desenvolvida com a participação dos diversos grupos. Ao invés de optar por "receitas universais", as quais ela chama de "verdadeiras panaceias", os governantes deveriam experimentar a governança coletiva. 


\section{Limitações e contribuições do estudo}

A dificuldade de acesso às lideranças locais se configurou em uma limitação da pesquisa. É possível que a utilização de outros meios de coleta de dados e também a utilização de empresas especializadas para essa atividade minimizem tais limitações e revelem resultados mais concisos.

O estudo contribui ao oferecer uma reflexão autônoma e crítica da universidade sobre as limitações desse modelo de desenvolvimento que foi implantado no território.

Contribui ainda de forma relevante para o desenvolvimento do estudo na área da Economia Institucional, assim como possibilita uma abertura de frentes de pesquisas na área da Governança Territorial.

\section{Referências bibliográficas}

ASSOCIAÇÃO DOS GEÓGRAFOS BRASILEIROS - AGB. Seção Local Rio-Niterói Grupo de Trabalho em Assuntos Agrários. Relatório dos Impactos Socioambientais do Complexo Industrial-Portuário do Açu. Rio de Janeiro, 2011.

ATHAIDE, K.; RIBEIRO, C. A. Elementos Essenciais de Capital Social: uma investigação no Sistema Produtivo COAGRO. Revista Brasileira de Gestão e Desenvolvimento Regional, G\&DR, Taubaté, vol. 7, n. 3, pp. 212-232, 2011.

BARDIN L. Análise de conteúdo. Lisboa: Edições 70; 1977

BARRETO, S. M. N.; JÚNIOR, Q. P. L. A (re)produção do espaço capitalista nas áreas de grandes empreendimentos: uma análise comparativa entre os conflitos socioambientais nos Complexos Portuários do Açu e de Suape. Boletim do Observatório Ambiental Alberto Ribeiro Lamego, Campos dos Goytacazes/RJ, vol. 6, n. 1, pp. 57-67, jan./jun. 2012.

BEKER, H. Métodos de Pesquisa em Ciências Sociais. 4. ed. São Paulo: Hucitec, 1999.

BUENO P. N. Lógica da Ação Coletiva, Instituições e Crescimento Econômico: Uma Resenha Temática sobre a Nova Economia Institucional. EconomiA, Brasília(DF), vol. 5, n. 2, pp. 361420, jul./dez. 2004.

BUENO, N. P. Introdução a Dinâmica de Sistemas: com aplicação para a economia. Viçosa, MG: Ed. UFV, 2011.

BÜTTENBENDER, L. P. Arranjos Institucionais, cooperação e desenvolvimento: redes econômicas, tecnológicas: sementes do desenvolvimento agregando valor. Ed. Unijuí, 2010. 152p.

CAMPOS G. J. C. MÉTODO DE ANÁLISE DE CONTEÚDO: ferramenta para a análise de dados qualitativos no campo da saúde. Rev Bras Enferm, Brasília (DF) 2004 set./out. vol. 57, n. 5, pp. 611-4, 2004.

CERVO, A L. Metodologia científica. 3. ed. São Paulo: McGraw-Hill do Brasil, 1983. O método cientifico p. 23.

CONCEIÇÃO, A. O. A dimensão institucional do processo de crescimento econômico: inovações e mudanças institucionais, rotinas e tecnologia social. Economia e Sociedade, Campinas, vol. 17, n. 1 (32), p. 85-105, abr. 2008. 
CONCEIÇÃO, C. A. O. A contribuição das abordagens institucionalistas para a constituição de uma teoria econômica das instituições. Ensaios FEE, Porto Alegre, vol. 23, pp. 77-106, 2002.

GIL, A. C. Métodos e técnicas de pesquisa social. São Paulo: Atlas, 1999.

. Como Elaborar Projetos de Pesquisa. 4. ed. São Paulo: Atlas, 2002.

GOMES, W. P. A.; BUENO, P. N.; GOMES, P. A. Nova Economia Institucional e Capital Social: Uma Revisão Teórica. 2008. Disponível em: <www.sober.org.br/palestra/12/13P566>. Acesso em: 09 ago. 2012.

HODGSON, M. G. The Approach of Institutional Economics. Journal of Economic Literature, vol. 36, n. 1, pp. 166-192, mar. 1998. Disponível em: <http://www.jstor.org/stable/2564954>. Acesso em 10 mar. 2012.

JÚNIOR, Q. P. L.; FARIA, P. J. T.; CARVALHO, S. L. Implantação de um Complexo Industrial Portuário: o Caso do Porto do Açu. Agenda Social, vol. 5, n. 2, pp. 84-103, maio/ago. 2011.

MELO JUNIOR, J. A Ação Coletiva e Seus Interpretes. Pensamento Plural, n. 01, pp. 65-87, Pelotas, jul./dez. 2007.

MULS, M. L. Desenvolvimento Local, Espaço e Território: O Conceito de Capital Social e a Importância da Formação de Redes entre Organismos e Instituições Locais. EconomiA, Brasília, vol. 9, n. 1, pp. 1-21, 2008.

NORTH, D. C. Institutions, Institutional Change and Economic Performance. New York: Cambridge International Press, 1990.

NUNES, M. E. Reestruturação agrícola, instituições e desenvolvimento rural no Nordeste: dinâmicas regionais e a diversificação da agricultura familiar no Pólo Assu-Mossoró (RN). 2009. Tese (Doutorado em Desenvolvimento Rural). Universidade Federal do Rio Grande do Sul, Porto Alegre. Disponível em: <htp://www.lume.ufrgs.br/bitstream/ handle/10183/18314/000724991.pdf?sequence=1>. Acesso em 21 dez. 2012.

NUNES, M. E.; SCHNEIDER, S. Reestruturação Agrícola, Instituições e Desenvolvimento Rural no Nordeste: a diversificação da agricultura familiar do Pólo Açu-Mossoró (RN). Revista Econômica do Nordeste-REN, vol. 43, n. 4, 2012.

OSTROM, E. A diagnostic approach for going beyond panaceas. Worcester: Clark University, 2007.

PEDLOWSKI, M.; ALVARENGA, F. Development Projects and the Need for Participatory and Transparent Channels of Negotiation with affected Communities. In: ANNUAL WORLD BANK CONFERENCE ON LAND AND POVERTY, Washington, 2013.

RIBEIRO, C. A.; BODEN, S. L. Organização produtiva da pesca oceânica artesanal em São João da Barra - RJ. Vértices, Campos dos Goytacazes, vol. 14, n. 1, p. 121-136, jan./abr. 2012.

RIBEIRO, C. A.; SANTOS, E. W. M.; SOUSA, R. S. Aglomeração Produtiva do Complexo Portuário do Açu: Aspectos de sua Natureza e Perspectivas Evolucionárias. In: XXXI ENCONTRO NACIONAL DE ENGENHARIA DE PRODUÇÃO. Belo Horizonte, 2011.

SALLES, O. S. Repensando desenvolvimento econômico no século XXI: Instituições, sustentabilidade e outros desafios. Agenda Social, vol. 5, n. 2, pp. 1- 23, 2011. 
SALLES, A. O. T.; RIBEIRO, L. P. Instituições, desenvolvimento econômico e sustentabilidade: uma análise dos mecanismos de regulamentação das políticas de meio ambiente. In: VI ENCONTRO DE ECONOMIA CATARINENSE, Joinvile: UNIVILLE, 2012.

SELLTIZ, C.; WRIGHTSMAN, L.; COOK, S. Métodos de Pesquisa nas Relações Sociais. 2. ed. São Paulo: Pedagógica e Universitária LTDA, 1987.

SILVA, D. M. Governança Territorial no Arranjo Produtivo Local de Turismo de Bonito/ Serra da Bodoquena e o Desenvolvimento Local. 2007. 114f. Dissertação (Mestrado em Desenvolvimento Local). Universidade Católica Dom Bosco, Campo Grande - MS, 2007.

SOUZA, N. T.; TERRA, P. R.; OLIVEIRA, S. P. V. Implantação do Complexo Portuário do Açu e atividade de pesca artesanal marinha do Norte Fluminense: um conflito socioambiental. Boletim do Observatório Ambiental Alberto Ribeiro Lamego, Campos dos Goytacazes/RJ, vol. 3, n. 2, pp. 23-30, 2009.

TEIXEIRA, D. J. R. Ação Coletiva em Alberto Mellucci. 2008. Disponível em: < http://www. didinho.org/ArtigoMelucci.pdf>. Acesso em: 09 jan. 2013.

WILLIAMSON, O. E. Calculativeness, Trust, and Economic Organization. Journal of Law and Economics. vol. 36, n. 1, Part 2, Chicago, 1993. Disponível em: http://nkuie.org/wp-content/ uploads/2013/06/2calculativeness-trust-and-economic-organiztion.pdf. Acesso em 01 ago 2012.

. The New Institutional Economics: Taking Stock, Looking Ahead. Journal of Economic Literature, pp. 595-613, 2000. Disponível em: <htp://www.llx.com.br/pt/superporto-do-acu/ Paginas/o-empreendimento.aspx>. Acesso em 06 jan. 2013.

YIN, R. K. Estudo de caso: planejamento e métodos. 3. ed. Porto Alegre: Bookman, 2005. 